\title{
Effervescence Assisted Fusion Technique to Enhance the Solubility of Drugs
}

\author{
Mohd Aftab Alam, ${ }^{1,3}$ Fahad I. Al-Jenoobi, ${ }^{1}$ Abdullah M. Al-Mohizea, ${ }^{1}$ and Raisuddin Ali ${ }^{2}$
}

Received 19 February 2015; accepted 28 July 2015; published online 12 August 2015

\begin{abstract}
The solubility of five poorly soluble drugs was enhanced by using an effervescence assisted solid dispersion (EASD) technique. EASDs were prepared by using modified fusion method. Drug and hydrophilic carrier were melted, and in this molten mixture, effervescence was generated by adding effervescence couple comprising organic acid (citric acid) and carbonic base (sodium bicarbonate). Solubility of drug powders, solid dispersions, and EASDs was determined at $25^{\circ} \mathrm{C}$ using shake flask method. Atorvastatin calcium, cefuroxime axetil, clotrimazole, ketoconazole, and metronidazole benzoate were estimated using a spectrophotometer at $246,280,260,230$, and $232 \mathrm{~nm}\left(\lambda_{\max }\right)$, respectively. Solubility of atorvastatin calcium (from 100 to $345 \mu \mathrm{g} / \mathrm{ml}$ ), cefuroxime axetil (from 441 to $1948 \mu \mathrm{g} / \mathrm{ml}$ ), clotrimazole (from 63 to $677 \mu \mathrm{g} / \mathrm{ml}$ ), ketoconazole (from 16 to $500 \mu \mathrm{g} / \mathrm{ml}$ ), and metronidazole benzoate (from 112 to $208 \mu \mathrm{g} / \mathrm{ml}$ ) in EASDs was enhanced by 3.45-, 4.4-, 10.7-, 31.2-, and 1.8-fold, respectively. Scanning electron micrographs of drug powder, solid dispersion, and EASDs were compared. Scanning electron micrographs of EASDs showed a uniform distribution of drug particles in the carrier matrix. Morphology (size and shape) of cefuroxime axetil particles was altered in solid dispersion as well as in EASD. EASDs showed better solubility enhancement than conventional solid dispersions. The present technique is better suitable for drugs having a low melting point or melt without charring. Effervescence assisted fusion technique of preparing solid dispersions can be employed for enhancing solubility, dissolution, and bioavailability of poorly soluble drugs.
\end{abstract}

KEY WORDS: dissolution; effervescence; fusion; solid dispersion; solubility.

\section{INTRODUCTION}

Oral bioavailability of drugs is directly related with their solubility and permeability. According to the biopharmaceutics classification system (BCS) classification, the drugs of class II and IV have low solubility (1). The solubility and bioavailability of poorly soluble drugs has been improved by several techniques including particle size reduction, complex formation, nanotechnologies, solid dispersion, polymeric micelle, salt formation, prodrugs, polymorphs, and solvates (2-4). Each of these techniques has its pros and cons. Different solubilization techniques may have different influence on the solubility and other physicochemical characteristics of the same drug molecule $(3,4)$. So, there is no universal technology which can be used in all cases of solubility enhancement, while preserving the safety and efficacy of drugs. Among these techniques of solubility enhancement, solid dispersion seems to be an easy and simple technique. In solid dispersion, a poorly soluble drug substance is dispersed in a quickly water soluble solid carrier matrix (4). These water

\footnotetext{
${ }^{1}$ Department of Pharmaceutics, College of Pharmacy, King Saud University, Riyadh, Kingdom of Saudi Arabia.

${ }^{2}$ Research Centre, Pharmaceutical Chemistry, College of Pharmacy, King Saud University, Riyadh, Kingdom of Saudi Arabia.

${ }^{3}$ To whom correspondence should be addressed. (e-mail: afealam@rediffmail.com)
}

soluble carriers include mannitol, lactose, urea, polyethylene glycol, Gelucire, poloxamer 127, etc. Quickly water soluble carrier dissolved rapidly and exposes the drug particles with increased surface area and augments the rate of dissolution. Selection of a carrier is an important step for preparing solid dispersion since the physical stability of the dispersion depends on the miscibility of drug with carrier matrix (5).

Binary or ternary solid dispersions have been reported to be more successful since they provide physical stability and prevents recrystallization of drug $(4,6-9)$. Use of surfactant with carrier enhances the wettability and solubilization of the drug and also assists in drug release (10-12). Methods for preparing solid dispersion are fusion (melt), spray drying, solvent evaporation, lyophilization, spray congealing, supercritical fluids and twin screw extruder, etc. (4). Physicochemical characteristics of a drug in solid dispersion may be affected by process, process variables, and carrier compositions $(13,14)$. He et al. reported that spray freeze drying process provides physically and chemically stable amorphous solid dispersion of baicalein, while the dispersion prepared by solvent evaporation showed recrystallization of the drug (14). Solid dispersions of indomethacin in mannitol/urea were prepared by fusion and effervescence assisted fusion techniques; the effervescence assisted fusion technique enhances the solubility and dissolution better than the conventional method (15). Solid dispersion of an anticancer compound ( $\mathrm{T}-\mathrm{OA}$ ) in 
Table I. Solubility of Atorvastatin Calcium (AT), Clotrimazole (CZ), Ketoconazole (KZ), Metronidazole Benzoate (MB), and Cefuroxime Axetil (CA); their Solid Dispersion (SD); and Effervescence Assisted Solid Dispersions (EASD)

\begin{tabular}{llll}
\hline Name of drug & \multicolumn{2}{l}{ Solubility $(\mu \mathrm{g} / \mathrm{ml})$} & \\
\cline { 2 - 4 } \cline { 3 - 4 } & Drug & Solid dispersion & EASD \\
\hline Atorvastatin calcium & 100 & 164 & 345 \\
Clotrimazole & 63 & 112 & 677 \\
Ketoconazole & 16 & 22 & 500 \\
Metronidazole benzoate & 112 & 165 & 208 \\
Cefuroxime axetil & 441 & - & 1948 \\
\hline
\end{tabular}

polyvinylpyrrolidone (PVP) K-30 prepared by the solvent evaporation method improves the solubility, dissolution, and bioavailability of the compound (16).

Solubility, dissolution, and in vitro antifungal activity of clotrimazole was improved by its solid dispersion in polyvinyl pyrrolidones (K-17, K-25, and K-30) (17). Chen et al. prepared solid dispersions of griseofulvin, felodipine, and ketoconazole in PVP-VA or HPMC-AS. Because of low crystallization tendency and strong drug-carrier interaction, solid dispersion of ketoconazole in HPMC-AS outperformed all others (18). Solid dispersion of ketoconazole in nicotinamide improves its solubility and dissolution (19). Solid dispersions of atorvastatin calcium were prepared in Soluplus ${ }^{\circledR}$ (20), modified locust bean gum (21), polyvinylpyrrolidone vinyl acetate (22), and poly(ethylene glycol) 6000 (23) to improve its solubility, dissolution, and bioavailability. Dissolution of cefuroxime axetil was improved with HPMC 2910/PVP K-30 solid dispersion (24). Solid dispersion of cefuroxime axetil with Gelucire 50/ 13 and Aerosil 200 showed superior bioavailability compared to its solid dispersion with polyvinyl pyrrolidone, and its amorphous form (25). The reported aqueous solubility of atorvastatin calcium, cefuroxime axetil, clotrimazole, ketoconazole, and metronidazole benzoate was $\geq 100 \mu \mathrm{g} / \mathrm{ml}(26,27)$, about $300 \mu \mathrm{g} / \mathrm{ml}$ (28), $55 \mu \mathrm{g} / \mathrm{ml}$ (29), $17 \mu \mathrm{g} / \mathrm{ml}(30)$, and $122 \mu \mathrm{g} / \mathrm{ml}$ (http://products.sanofi.com.au/aus_pi_flagylS.pdf), respectively.

The present investigation has modified the solid dispersion technique (fusion) and compared its application on solubility enhancement of poorly soluble drugs with conventional fusion technique. For this comparison, five poorly soluble drugs (atorvastatin calcium, cefuroxime axetil, clotrimazole, ketoconazole, and metronidazole benzoate) were selected, and their solubility studies were carried out in water.

\section{MATERIALS AND METHODS}

Mannitol was purchased from BDH laboratories supplies (England). Citric acid was obtained from Avon-chem (UK). Sodium bicarbonate of BDH laboratory reagents Poole, England, was used. Spectrophotometer was of Jasco V-530. Drug samples were obtained as a gift from Tabuk Pharm. Ltd. Differential scanning calorimeter was of Shimadzu (DSC-60 instrument). Scanning electron microscope was of Zeiss EVO LS10 (Cambridge, UK).

\section{Preparation of Solid Dispersion}

Solid dispersions of atorvastatin calcium, cefuroxime axetil, clotrimazole, ketoconazole, and metronidazole benzoate were prepared by melting (fusion) method. Mannitol was melted in a borosilicate glass beaker, and drug powder of each individual drug was added separately to the molten mannitol (drug/mannitol, 1:5 ratio). The molten mixture of drug and carrier was continuously stirred to increase uniform distribution of components. This melted uniform mixture was quickly solidified at low temperature under cold condition (freezer). Cooled solid dispersions were crushed and ground gently using a mortar and pestle. The powdered solid dispersion of each drug was stored in a vacuum desiccator.

\section{Effervescence Assisted Solid Dispersion (EASD)}

Carrier (mannitol) was melted in a glass beaker (at $175-180^{\circ} \mathrm{C}$ ), and organic acid (citric acid) was added to the molten mannitol. This mixture of mannitol and organic acid was melted and uniformly mixed by continuous stirring. Powder of poorly soluble drug (atorvastatin calcium or cefuroxime axetil or clotrimazole or ketoconazole or metronidazole benzoate) was added to this molten mixture under continuous stirring. To the molten mixture of carrier-organic acid-drug, the sodium bicarbonate (carbonic base) was added under rapid stirring. The ratio of carbonic base and organic acid was according to their molar reactivity. Since one molecule of citric acid may react with three molecules of sodium bicarbonate, the quantity of citric acid was in 1:3 molar ratio of sodium bicarbonate. After addition of sodium bicarbonate, the effervescence (micro-bubbles) was generated due to acid-base reaction and the molten mixture turns into white froth (except for cefuroxime axetil). This frothy molten mixture was continuously stirred until the effervescence slowed down (about to seize). The froths were cooled down and allowed to solidify at low temperature (freezer). This cooled solid dispersion was crushed and ground gently using a mortar and pestle. Powdered EASD was stored in a desiccator.

\section{Solubility Studies}

Solubility measurements were performed by using shake flask method. The solubility studies of drugs, their solid dispersions, and EASD were carried out in water. 

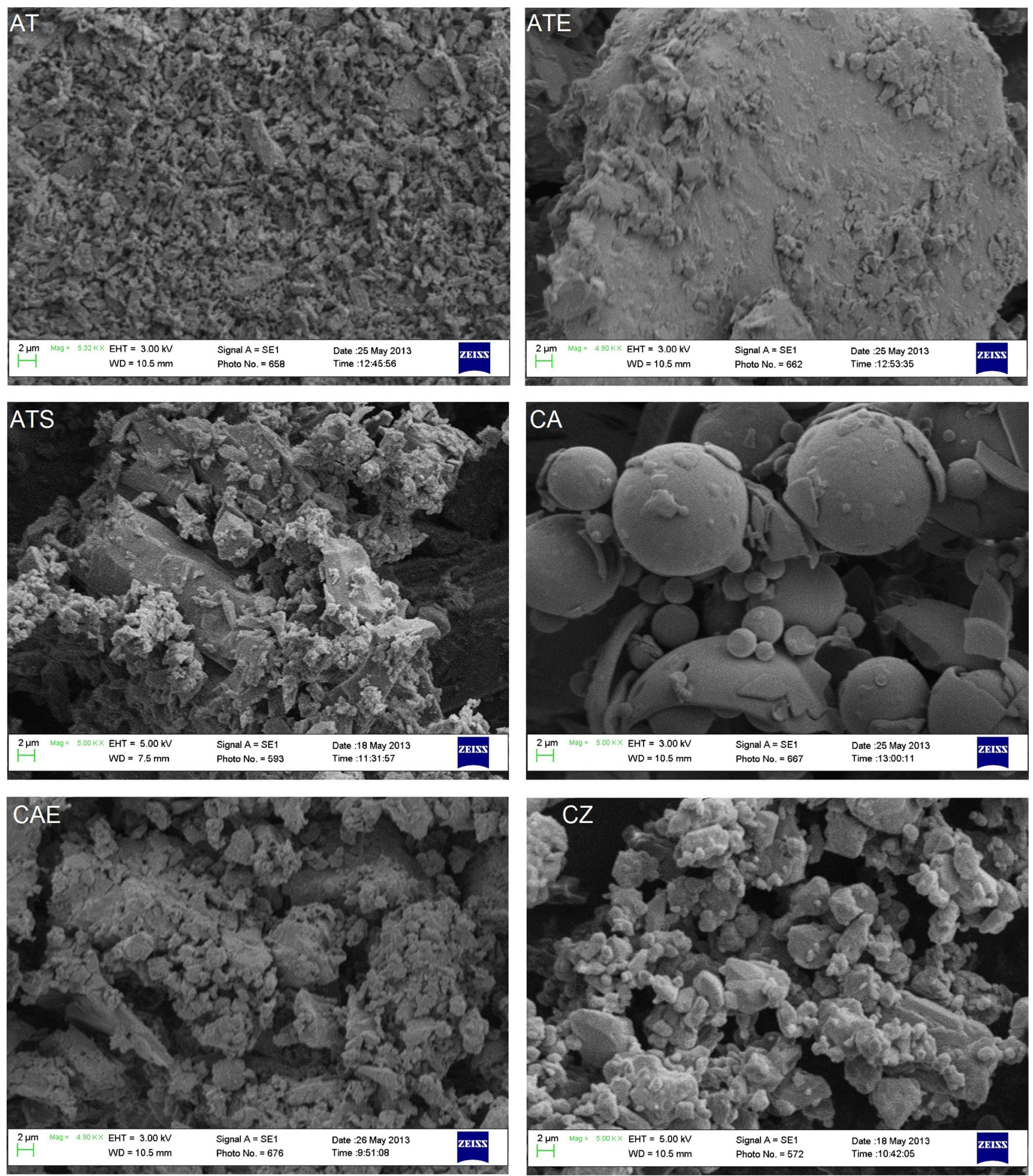

Fig. 1. Scanning electron micrographs of atorvastatin calcium $(A T)$, cefuroxime axetil $(C A)$, clotrimazole $(C Z)$, ketoconazole $(K Z)$, and metronidazole benzoate $(M B)$; their solid dispersion ( $A T S, C Z S, K Z S$, and $M B S$, respectively); and effervescence assisted solid dispersions ( $A T E, C A E, C Z E, K Z E$, and $M B E$, respectively)

The excess amount of each powder (drug, solid dispersion, and EASD) was separately added to the 25 -ml volumetric flasks comprising water $(15 \mathrm{ml})$, and these flasks were set over shaker water bath for $48 \mathrm{~h}$ at $25^{\circ} \mathrm{C}$, under continuous shaking $(80 \mathrm{rpm})$. After $48 \mathrm{~h}$, the samples were withdrawn, filtered, and analyzed by using a UV spectrophotometer. The solubility of drugs, their solid dispersions, and EASDs were calculated and compared. The $\mathrm{pH}$ values of solubility media (water), mannitol solution $(30 \mathrm{mg} / \mathrm{ml})$, and solutions of EASDs $(30 \mathrm{mg} / \mathrm{ml})$ of individual drugs were measured at $22^{\circ} \mathrm{C}$ using a $\mathrm{pH}$ meter (Seven Easy $\mathrm{pH}$; Mettler ToledoAG, Switzerland). 

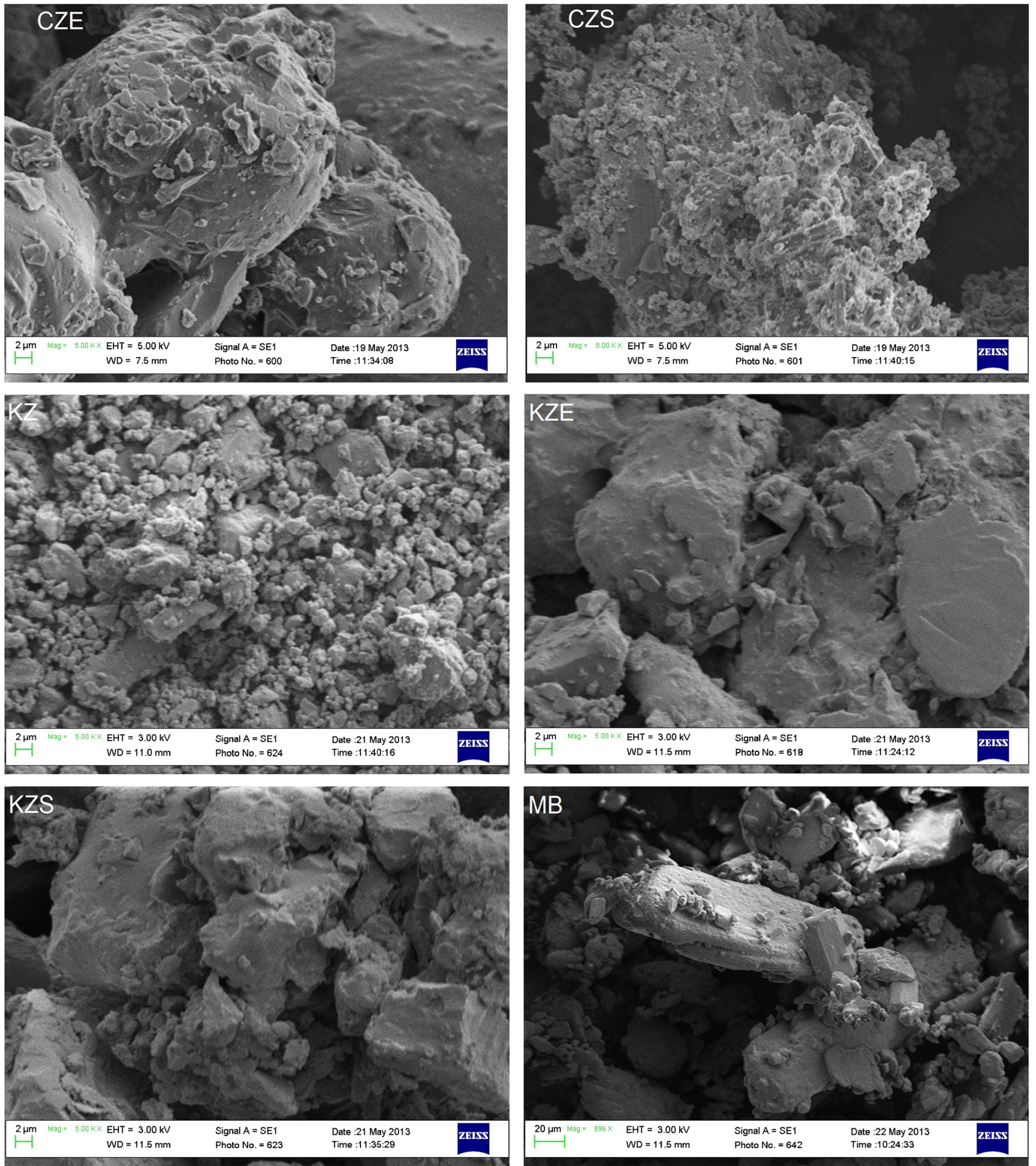

Fig. 1. (continued)

\section{Sample Analysis}

Stock solutions of each individual drug (atorvastatin calcium, cefuroxime axetil, ketoconazole, and metronidazole benzoate) in methanol were diluted with water or water/methanol mixture $(70: 30)$ to prepare standard

solutions. These standard solutions were used for preparing calibration curves. Atorvastatin calcium, cefuroxime axetil, clotrimazole, ketoconazole, and metronidazole benzoate were estimated at 246, 280, 260, 230, and $232 \mathrm{~nm}$ $\left(\lambda_{\max }\right)$, respectively. The value of regression coefficient of each calibration curve was higher than 0.998 . 


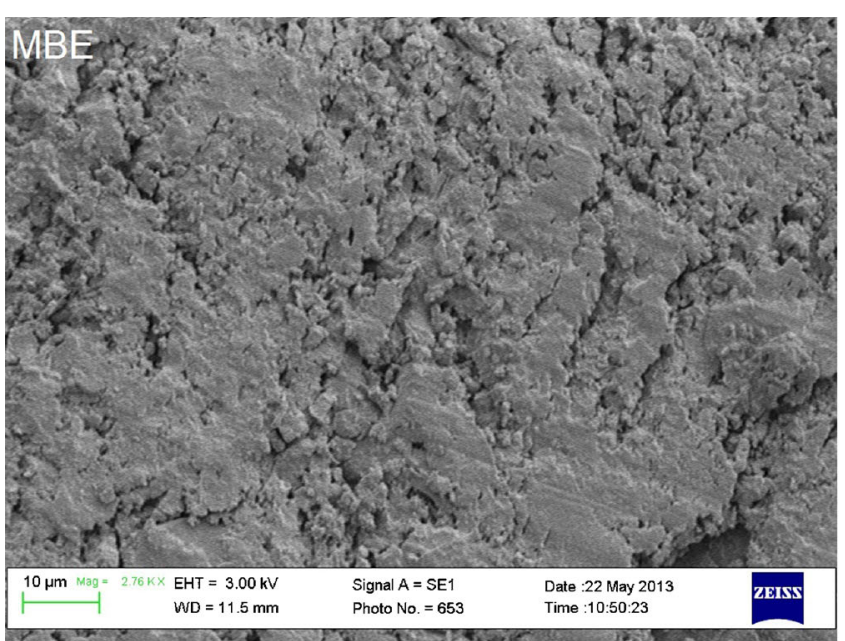

Fig. 1. (continued)

\section{Scanning Electron Microscopy}

Micrographs of the samples (drug, solid dispersion, and EASD) were taken using a scanning electron microscope (SEM) (Zeiss EVO LS10; Cambridge, UK). Powder samples were fixed on stubs using both sides of an adhesive carbon tape (SPI Supplies, West Chester, USA) and coated under vacuum with gold in a Q150R sputter coater unit from Quorum Technologies Ltd. (East Sussex, UK) in an argon atmosphere at $20 \mathrm{~mA}$ for $60 \mathrm{~s}$.

\section{Differential Scanning Calorimetry (DSC)}

Thermal analysis was performed for drug powders, solid dispersions, and effervescence assisted solid dispersions of atorvastatin calcium, cefuroxime axetil, clotrimazole, ketoconazole, and metronidazole benzoate using a Shimadzu DSC60 instrument. The aluminum pans were filled with samples comprising about $2-4 \mathrm{mg}$ of drug. The filled aluminum pans were crimped and hermetically sealed. Nitrogen gas was supplied at a flow rate of $40 \mathrm{ml} / \mathrm{min}$. Samples were heated at the rate of $10^{\circ} \mathrm{C} / \mathrm{min}$, in the range of 50 to $300^{\circ} \mathrm{C}$.

\section{RESULTS AND DISCUSSION}

The solubility results of atorvastatin calcium, cefuroxime axetil, clotrimazole, ketoconazole, and metronidazole benzoate; their solid dispersions; and effervescence assisted solid dispersions are presented in Table I. Water solubility of atorvastatin calcium, cefuroxime axetil, clotrimazole, ketoconazole, and metronidazole benzoate at $25^{\circ} \mathrm{C}$ was observed as $100,441,63,16$, and $112 \mu \mathrm{g} / \mathrm{ml}$, respectively. The investigated solubility of these drugs was approximately close to the reported values (http://products.sanofi.com.au/ aus_pi_flagylS.pdf) (26-30). Solid dispersions of atorvastatin calcium, clotrimazole, ketoconazole, and metronidazole benzoate did not show remarkable enhancement in the solubility of these drugs (see Table I). The simple reason for this low effect on solubility may be the insignificant impact of fusion process on the active surface area of dispersed drug particles or on the crystallinity of drugs. Effervescence assisted solid

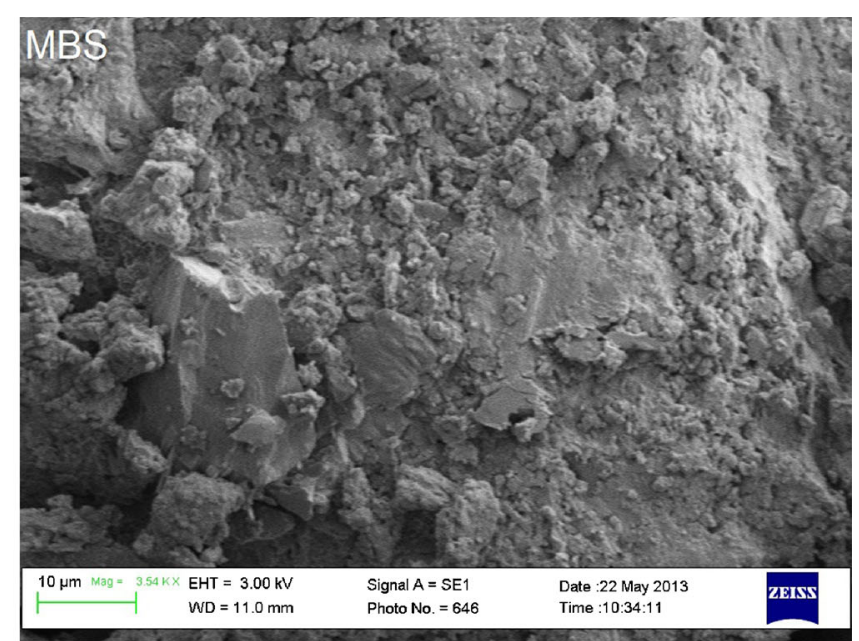

dispersion of atorvastatin calcium, cefuroxime axetil, clotrimazole, ketoconazole, and metronidazole benzoate showed a remarkable enhancement in the aqueous solubility of these drugs. Amplitude of solubility enhancement through effervescence assisted solid dispersion was atorvastatin calcium 3.45fold $(345 \mu \mathrm{g} / \mathrm{ml})$, cefuroxime axetil 4.4 -fold $(1948 \mu \mathrm{g} / \mathrm{ml})$, clotrimazole 10.7-fold $(677 \mu \mathrm{g} / \mathrm{ml})$, ketoconazole 31.2-fold $(500 \mu \mathrm{g} / \mathrm{ml})$, and metronidazole benzoate 1.8 -fold $(208 \mu \mathrm{g} / \mathrm{ml})$. The $\mathrm{pH}$ values of water and mannitol solution in water were 7.41 and 7.23, respectively. The $\mathrm{pH}$ values of EASDs of atorvastatin calcium, cefuroxime axetil, clotrimazole, ketoconazole, and metronidazole benzoate were 7.21, 6.65, 7.57, 7.52, and 6.75 , respectively. Since the change in the $\mathrm{pH}$ value of solubility media of EASDs was not so extensive that it may significantly affect the solubility of these drugs, it can be concluded that $\mathrm{pH}$ of the media is not the real factor behind solubility enhancement of EASDs. Scanning electron micrographs of atorvastatin calcium, cefuroxime axetil, clotrimazole, ketoconazole, and metronidazole benzoate; their solid dispersion; and effervescence assisted solid dispersions are presented in Fig. 1. Scanning electron micrographs of pure drug samples reveal that the particles of these drugs are crystalline with different sizes and shapes. Atorvastatin calcium powder micrograph showed majority of irregular-shaped particles with few rod-shaped crystals (26). Atorvastatin particles were uniformly distributed through EASD, but distribution through conventional solid dispersion was comparatively non-uniform and aggregates of drug particles were observed. Change in shape or size of atorvastatin crystals is not interpreted since the particles were embedded in carrier matrix of EASD. Micrograph of cefuroxime axetil showed small and large disc-shaped particles. The particles of cefuroxime axetil in EASD showed drastic morphological changes by losing their integrated shape, and their size was also reduced (24). Clotrimazole micrograph showed crystalline particles of small size (average particle size $<3 \mu \mathrm{m}$ ) (31). Particles of clotrimazole were uniformly distributed through carrier matrix in EASD, but in conventional solid dispersion, few aggregates of small and large particles/crystals were observed. Ketoconazole drug particles were small in size (mean size 

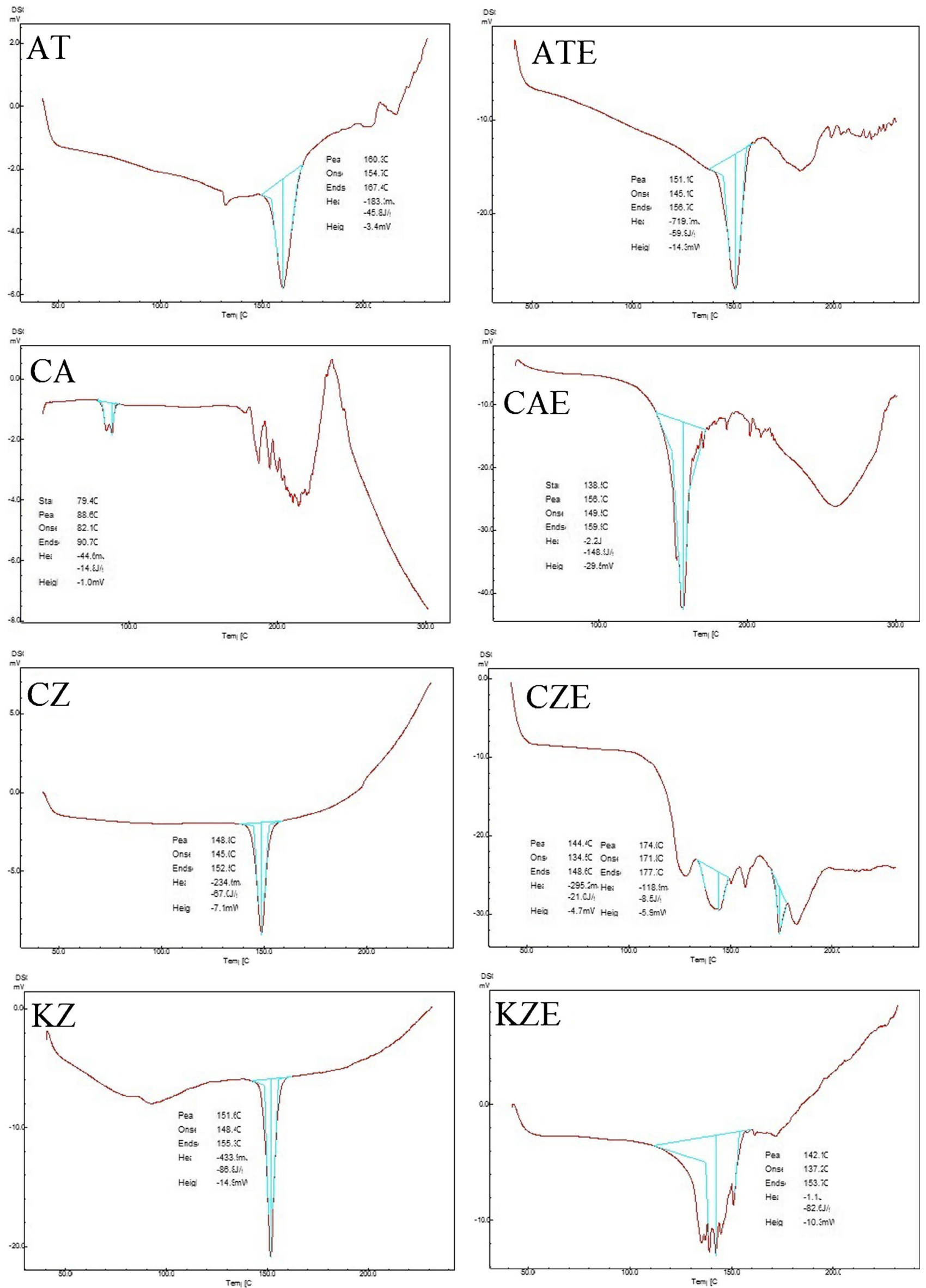

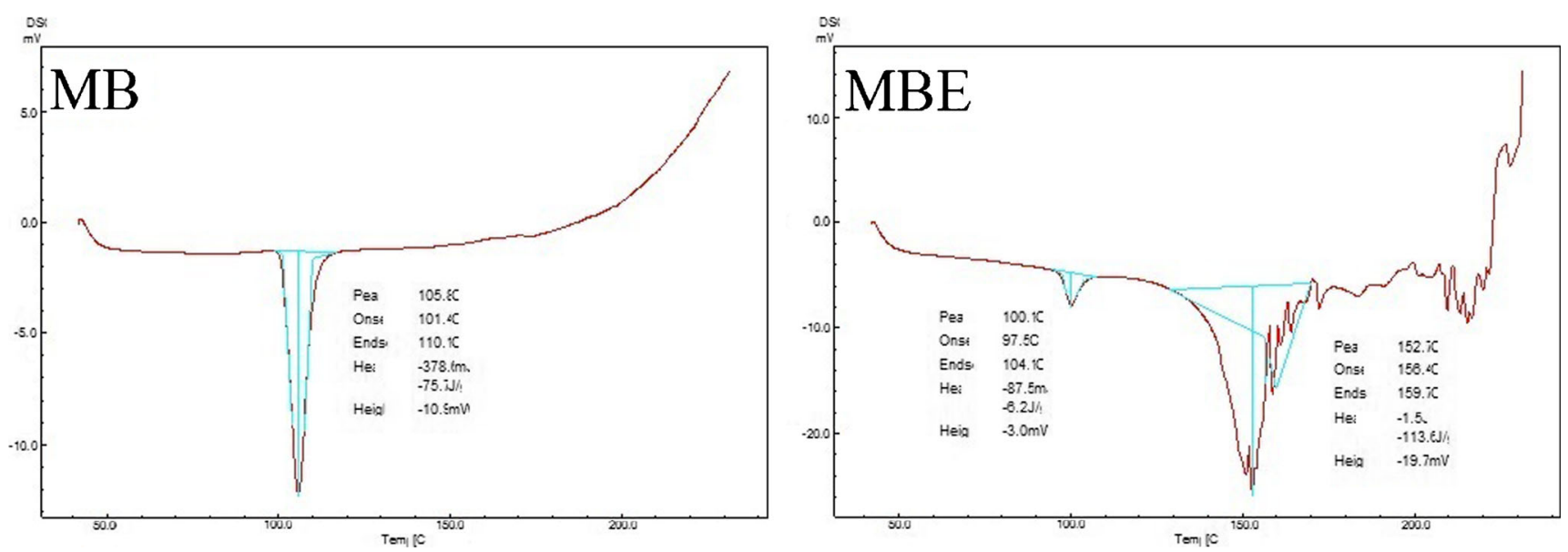

Fig. 2. (continued)

$<2 \mu \mathrm{m}$ ), and the micrograph showed aggregates of particles and some large solid crystals of distinct shape (32). Ketoconazole particles were uniformly distributed through solid dispersion and EASD. These small ketoconazole particles and their clusters were embedded throughout the carrier matrix. The micrographs of ketoconazole solid dispersion and EASD showed only few shaped crystals or aggregates of particles. Micrograph of metronidazole benzoate drug powder revealed a mixture of large rod-shaped crystals and small particles. The crystal shape of metronidazole benzoate powder resembled the monohydrate or dehydrated crystals (33). The drug was distributed throughout the carrier matrix in both the dispersions, and there was no appearance of distinct big size crystal in the carrier matrix.

The endotherms of differential scanning calorimetric study for atorvastatin calcium, cefuroxime axetil, clotrimazole, ketoconazole, and metronidazole benzoate drug substances, and their EASDs are presented in Fig. 2. Melting points of atorvastatin calcium, cefuroxime axetil, clotrimazole, ketoconazole, and metronidazole benzoate were observed at about 160, 88, 148,151 , and $105^{\circ} \mathrm{C}$, respectively (data taken from DSC endotherms). The sharp endotherms of these pure drug substances indicate their crystalline nature. DSC thermograms of EASDs of these drugs showed interaction between the drug substance and excipients since their melting point or peak features are different from drug powder. The endotherms of EASDs of clotrimazole and ketoconazole showed remarkable change in features (width and sharpness of peak) and can be interpreted as change (decrease) in the crystallinity of the drugs. Decrease in the crystalline features of a composition may be interpreted as the presence of amorphous form. The thermogram of EASD of cefuroxime axetil showed a distinctly new melting peak, which may be of its decomposed compound. It has been observed that cefuroxime axetil gives creamy-buff color to the composition when it was added to the molten mixture of mannitol and citric

Fig. 2. Differential scanning calorimetric thermograms of atorvastatin calcium $(A T)$, cefuroxime axetil $(C A)$, clotrimazole $(C Z)$, ketoconazole $(K Z)$, and metronidazole benzoate $(M B)$, and their effervescence assisted solid dispersions ( $A T E, C A E, C Z E, K Z E$, and $M B E$, respectively) acid. The monograph of cefuroxime axetil ( $\left.{ }^{\mathrm{Pr}} \mathrm{Ceftin} 囚\right)$ also reported that cefuroxime axetil decomposes below its melting point (http://www.gsk.ca/english/docs-pdf/Ceftin_PM\%20(201401-30).pdf).

In EASDs, the uniformly distributed drug particles with reduced particle size (and/or changed crystallinity/ salt form) showed improvement in solubility because these small drug particles were coated/confined within the water soluble carrier matrix and their active surface area was increased. On the basis of the above observations, it can be concluded that effervescence assisted solid dispersion is a novel formulation process which can be exploited to improve the solubility of drugs and alter the physicochemical characteristic. Effervescence assisted fusion technique for preparing solid dispersion is suitable for drug which melts without charring or decomposing. Drugs having higher melting point and tendency to degrade and char may not be good candidates for this technique. From the literature, it was also observed that the solubility of some drugs varies according to experimental conditions such as temperature, method, $\mathrm{pH}$ of solvent medium, duration of study (for unstable drugs), type of isomer, polymorph, and their ratio. The findings and observations of the present investigation suggested that the effervescence assisted fusion technique can be exploited as an important tool for solubility enhancement.

\section{CONCLUSION}

Effervescence assisted solid dispersion technique provides a remarkable increase in the solubility of tested poorly soluble drugs (atorvastatin calcium, cefuroxime axetil, clotrimazole, ketoconazole, and metronidazole benzoate). This technique can also be exploited for other poorly soluble drugs to enhance their solubility, dissolution, and bioavailability.

\section{ACKNOWLEDGMENT}

We thank the Research Centre, College of Pharmacy, King Saud University for funding this research project. 
Conflict of interest disclosure The authors declare that they have no competing interests.

\section{REFERENCES}

1. Amidon GL, Lennernäs H, Shah VP, Crison JR. A theoretical basis for a biopharmaceutic drug classification: the correlation of in vitro drug product dissolution and in vivo bioavailability. Pharm Res. 1995;12(3):413-20.

2. Alam MA, Al-Jenoobi FI, Al-Mohizea AM, Ali R. Understanding and managing oral bioavailability: physiological concepts and patents. Recent Pat Anticancer Drug Discov. 2015;10(1):87-96.

3. Alam MA, Al-Jenoobi FI, Al-Mohizea AM. Commercially bioavailable proprietary technologies and their marketed products. Drug DiscovToday. 2013;18(19-20):936-49.

4. Alam MA, Ali R, Al-Jenoobi FI, Al-Mohizea AM. Solid dispersions: a strategy for poorly aqueous soluble drugs and technology updates. Expert Opin Drug Deliv. 2012;9(11):1419-40.

5. Verma S, Rudraraju VS. A systematic approach to design and prepare solid dispersions of poorly water-soluble drug. AAPS PharmSciTech. 2014;15(3):641-57.

6. Al-Obaidi H, Buckton G. Evaluation of griseofulvin binary and ternary solid dispersions with HPMCAS. AAPS PharmSciTech. 2009;10(4):1172-7.

7. Noolkar SB, Jadhav NR, Bhende SA, Killedar SG. Solid-state characterization and dissolution properties of meloxicammoringa coagulant-PVP ternary solid dispersions. AAPS PharmSciTech. 2013;14(2):569-77.

8. Prasad D, Chauhan H, Atef E. Amorphous stabilization and dissolution enhancement of amorphous ternary solid dispersions: combination of polymers showing drug-polymer interaction for synergistic effects. J Pharm Sci. 2014;103(11):3511-23.

9. Mahmoudi ZN, Upadhye SB, Ferrizzi D, Rajabi-Siahboomi AR. In vitro characterization of a novel polymeric system for preparation of amorphous solid drug dispersions. AAPS J. 2014;16(4):685-97.

10. Mura P, Moyano JR, González-Rodríguez ML, Rabasco-Alvaréz AM, Cirri M, Maestrelli F. Characterization and dissolution properties of ketoprofen in binary and ternary solid dispersions with polyethylene glycol and surfactants. Drug Dev Ind Pharm. 2005;31(4-5):425-34.

11. Dave RH, Patel HH, Donahue E, Patel AD. To evaluate the change in release from solid dispersion using sodium lauryl sulfate and model drug sulfathiazole. Drug Dev Ind Pharm. 2013;39(10):1562-72.

12. Szuts A, Láng P, Ambrus R, Kiss L, Deli MA, Szabó-Révész P. Applicability of sucrose laurate as surfactant in solid dispersions prepared by melt technology. Int J Pharm. 2011;410(1-2):107-10.

13. Paudel A, Van den Mooter G. Influence of solvent composition on the miscibility and physical stability of naproxen/PVP K 25 solid dispersions prepared by cosolvent spray-drying. Pharm Res. 2012;29(1):251-70.

14. He X, Pei L, Tong HH, Zheng Y. Comparison of spray freeze drying and the solvent evaporation method for preparing solid dispersions of baicalein with Pluronic F68 to improve dissolution and oral bioavailability. AAPS PharmSciTech. 2011;12(1):104-13.

15. Alam MA, Al-mohizea AM, Al-juffali IA, Al-Jenoobi FI. Method for preparing a solid dispersion, solid dispersion obtained thereby and use thereof. EP2649989 A1. Publication date. Oct 16, 2013.
16. Hou P, Ni J, Cao S, Lei H, Cai Z, Zhang T, et al. Preparation and evaluation of solid dispersions of a new antitumor compound based on early-stage preparation discovery concept. AAPS PharmSciTech. 2013;14(2):629-38.

17. Balata $\mathrm{G}$, Mahdi M, Bakera RA. Improvement of solubility and dissolution properties of clotrimazole by solid dispersions and inclusion complexes. Indian $\mathrm{J}$ Pharm Sci. 2011;73(5):517-26.

18. Chen Y, Liu C, Chen Z, Su C, Hageman M, Hussain M, et al. Drugpolymer-water interaction and its implication for the dissolution performance of amorphous solid dispersions. Mol. Pharm. 2015.

19. Aggarwal AK, Jain S. Physicochemical characterization and dissolution study of solid dispersions of ketoconazole with nicotinamide. Chem Pharm Bull (Tokyo). 2011;59(5):629-38.

20. Ha ES, Baek IH, Cho W, Hwang SJ, Kim MS. Preparation and evaluation of solid dispersion of atorvastatin calcium with Soluplus ${ }^{\circledR}$ by spray drying technique. Chem Pharm Bull (Tokyo). 2014;62(6):545-51.

21. Panghal D, Nagpal M, Thakur GS, Arora S. Dissolution improvement of atorvastatin calcium using modified locust bean gum by the solid dispersion technique. Sci Pharm. 2013;82(1):177-91.

22. Kim MS, Kim JS, Cho W, Park HJ, Hwang SJ. Oral absorption of atorvastatin solid dispersion based on cellulose or pyrrolidone derivative polymers. Int J Biol Macromol. 2013;59:138-42.

23. Maurya D, Belgamwar V, Tekade A. Microwave induced solubility enhancement of poorly water soluble atorvastatin calcium. J Pharm Pharmacol. 2010;62(11):1599-606.

24. Jun SW, Kim MS, Jo GH, Lee S, Woo JS, Park JS, et al. Cefuroxime axetil solid dispersions prepared using solution enhanced dispersion by supercritical fluids. J Pharm Pharmacol. 2005;57(12):1529-37.

25. Dhumal RS, Biradar SV, Aher S, Paradkar AR. Cefuroxime axetil solid dispersion with polyglycolized glycerides for improved stability and bioavailability. J Pharm Pharmacol. 2009;61(6):743-51.

26. Shete G, Puri V, Kumar L, Bansal AK. Solid state characterization of commercial crystalline and amorphous atorvastatin calcium samples. AAPS PharmSciTech. 2010;11(2):598-609.

27. Machado JC, Lange AD, Todeschini V, Volpato NM. Development and validation of a discriminative dissolution method for atorvastatin calcium tablets using in vivo data by LC and UV methods. AAPS PharmSciTech. 2014;15(1):189-97.

28. Murshedkav T. Effect of crystalline to amorphous conversions on solubility of cefuroxime axetil. 2002. Open Access Master's Theses. Paper 270. http://digitalcommons.uri.edu/theses/270.

29. Prabagar B, Yoo BK, Woo JS, Kim JA, Rhee JD, Piao MG, et al. Enhanced bioavailability of poorly water-soluble clotrimazole by inclusion with beta-cyclodextrin. Arch Pharm Res. 2007;30(2):249-54.

30. Kovács K, Stampf G, Klebovich I, Antal I, Ludányi K. Aqueous solvent system for the solubilization of azole compounds. Eur J Pharm Sci. 2009;36(2-3):352-8.

31. Das S, Ng WK, Tan RB. Are nanostructured lipid carriers (NLCs) better than solid lipid nanoparticles (SLNs): development, characterizations and comparative evaluations of clotrimazole-loaded SLNs and NLCs? Eur J Pharm Sci. 2012;47(1):139-51.

32. Rasenack N, Müller BW. Dissolution rate enhancement by in situ micronization of poorly water-soluble drugs. Pharm Res. 2002;19(12):1894-900.

33. Hoelgaard A, Møller N. Hydrate formation of metronidazole benzoate in aqueous suspensions. Int J Pharm. 1983;15(2):213-21. 